\title{
Research on the Relationship Between Online Gamer Identity and Game Loyalty
}

\author{
Guo Zhao and Baolei Yang*
}

\author{
Jinan University \\ ${ }^{*}$ Corresponding author. Email: 862091828@qq.com
}

\begin{abstract}
With the continuous development of internet and communication technology, human have also increasingly expanded social interactions. The proportion of traditional face-to-face communication has decreased in daily life, while conveying information through media becomes the principal part. CMC (Computer-Mediated Communication) is not only the center of our life,but also the hotspot attracting more and more attention among specialists and scholars. Online game, one of the forms of CMC, has been attached increasing importance by scholars as a result of its constant development. Based on previous researches and from perspectives of social identity, social presence and social capital theory, this thesis studies various indexes of online game players through on-line and off-line questionnaires, including social network, sense of community, mutual dependence, converted capital and game identity. Based on the survey, this thesis will answer 3 key questions, including the relationship between online gamer identity and game loyalty, different online game behaviors with different gamer identity and indexes influencing online gamer identity and game loyalty. According to data analysis results, gamer identity has significant influence on the persistent behavior of playing on-line games. Besides, among those indexes which can affect the persistent behavior of playing on-line games, gamer identity is obviously relevant to indexes found in previous researches. In general, play frequency, network convergence and relational switching costs are important indexes which can influence on-line gamer identity and game loyalty. Through investigations on game loyalty from the perspective of social identity theory, this thesis not only enriches preceding researches of different disciplines within this field, such as psychology, sociology and communications, but also provides a new evidence for future researches on the online behaviors of online game players.
\end{abstract}

Keywords: Social identity, Social presence, Social capital, Online game.

\section{GENERAL INTRODUCTION}

The communication behavior in network society has always been the focus of academic circles. With the development of games, online games, as an important form of social networking, are attracting more and more attention. In 2019, the revenue of Chinese game market was about 288.48 billion yuan, with a year-on-year growth of $17.1 \%$. In 2019, there were about 660 million mobile game users in China, accounting for $77.92 \%$ of the total number of mobile Internet users in China. [1]

In this paper, the qualitative and quantitative methods are used to carry out relevant research. Qualitative research, referring to previous relevant studies, mainly adopts the literature research method and carries out theoretical construction on the two core concepts of "gamer identity" and "game loyalty".
Quantitative research mainly adopts the questionnaire survey method and provides online and paper questionnaires for game forums and college students, so as to provide data support for the research hypothesis and framework proposed by qualitative research.

In general, for the research of online games, scholars choose topics from a wide range of perspectives. The perspectives of domestic research mainly include the Internet addiction problem of teenagers, interpersonal communication in online games and the development history of online games. Foreign researches are mostly based on the perspective of industrial model and commercial profit. The research of this paper focuses on game loyalty. Compared to game addiction, game loyalty is more neutral in connotation. 
This paper is innovative mainly in the following two aspects: the innovation of theoretical reference and research starting point. Comparing the previous researches on game loyalty, this paper, focusing on ingroup identity, introduces the theory of social identity and analyzes the relationship between gamer identity and game loyalty. The starting point of paper is the development of the entire game industry, rather than focusing on the problem of young people's addiction of online games. Addiction is a psychological and physiological problem caused by excessive game playing. Game loyalty is concerned about the reasons affecting the normal gamer. In terms of the starting point, this paper is distinct from most domestic researches.

\section{THEORETICAL BACKGROUND AND RESEARCH HYPOTHESIS}

\subsection{Social Identity Theory}

Social identity theory, proposed by Tajfel and Turner, provides a new perspective on understanding group behavior. "That part of an individual's selfconcept which derives from his knowledge of his membership of a social group (or groups) together with the value and emotional significance attached to that membership"(Tajfel,1981).[2] Tajfel believes that social identity is the basis of individual group behavior, and individual concept is the value derived from subordinate groups. Based on Tajfel, Turner put forward Selfcategorization Theory. He believed that people always tried to identify themselves with a group. Through ingroup preferences and out-group biases, people tend to actively defend the values of their subordinate groups in order to gain or improve their own self-esteem.

As for the definition of in-group Identification, Linda R.Tropp wrote in "Ingroup Identification as theInclusion of Ingroup in the Self", the opinions of several predecessors were mentioned. Ingroup identity is the degree of perception of one's self-identification as a group member (Tuner et al., 1987). The definition of ingroup identity in Tropp's theory will be adopted. [3]

As far as online games are concerned, ingroup identity can also be regarded as gamer identity. On the basis of social identity theory, Frederik De Grove et al. (2015) apply social identity, especially Tuner selfclassification theory, to the self-classification of game players. "According to Turner(1986), there are two main determinants: immediate social situations in which social categorizations can emerge and the availability of preformed, culturally available classifications."[4] In their research, Frederik and others have come up with several indicators of player identity: Friendship environment, Play and Co-play frequency, Age and Gender. [5] If all the friends around you are fans of the game, the player will also think of himself as a player of the game. "It is also congruent with the work of identity theorists whom have pointed out that the activation of a social identity in specific social situations is associated with the degree to which that identity is embedded in one's social structure (Stets,Burke 2000; Stryker,Burke 2000)".

Previous studies have demonstrated a significant relationship between network convergence and gamer identity, so we can propose the first hypothesis in this paper.

H1: Gamer identity has a positive impact on network convergence.

\subsection{Social Presence Theory}

The social presence theory, first proposed by Heeter (1992), is an important theory in the study of CMC. With the development of communication technology, the boundary between time and space of interpersonal communication has been broken. The use of different media often gives us different feelings, which social psychology calls a sense of presence. Social presence plays a central role in online communication behavior (Kim, 2011). "The prevalence of high-speed Internet and the advancement of multimedia technologies make online games vivid communication media through which players can experience strong social presence."

Kim tried to explain the sense of social presence from four dimensions: a sense of community, mutual attention and support, open communication and affective connectedness.[6] In Kim and other relevant studies, the sense of community, compared with the other three dimensions, is the most significant in online games. A strong sense of community can stimulate players' loyalty to the game.

In online game communities, players often share their social resources, such as introducing friends to other gamers. This phenomenon is called "social networking convergence". With the integration of social networks, the interpersonal interaction and common interests between online game players are constantly increasing. It tends to create a sense of community. There are positive relationships between the social network convergence and the sense of community. Therefore, we can propose the second hypothesis of this paper.

H2: Gamer identity of players has a positive impact on the sense of community.

In a group, members often depend on each other to make decisions and take actions. This is called interdependence. Online gamers often have to join teams or rely on others to complete tasks, so emotions and opinions between players often influence players' behavior. This interdependence is a striking 
characteristic of in-groups. Therefore, we can propose the third hypothesis in this paper.

H3: Gamer identity has a positive impact on interdependence.

Social capital is used to describe the resources possessed by a social organization, which can promote mutual coordination and cooperation and increase mutual benefits. The capital includes rules and social trust, which exist in social networks and form among group members. With the increasing number of online game players, social capital also exists in cyberspace.

The behavior of online game players is often not isolated. Under the same goal, players tend to group together. Players spend a lot of time, not only entertaining themselves, but also consolidating and expanding their circle of friends. These online social networks are part of the players' social capital. When his/her friends are mostly interested in a particular game the player may not be willing to give up the game he is playing. This social capital, built on interpersonal relationships and generated by interacting with other players, is called relationship switching costs. Therefore, we can propose the fourth hypotheses in this paper.

H4: Gamer identity has a positive impact on the relationship switching costs

\subsection{Game Loyalty}

Online game addiction and game loyalty, in essence, are of the same nature. That is, players continue to follow and participate in online games. Previous research by Fan-Chen Tseng has pointed out four indicators for game loyalty. In the above assumptions, we have already explained those four indicators. In addition to the specific social and individual factors, we may make the last hypothesis of this paper.

H5: Gamer identity has a positive impact on game loyalty.

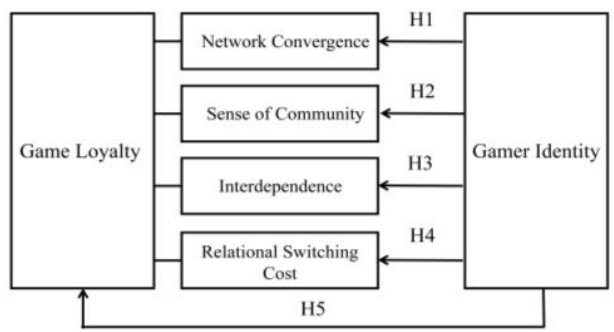

Figure 1 Theoretical framework.

\section{EMPIRICAL ANALYSIS AND HYPOTHESIS TESTING}

\subsection{Questionnaire Design, Distribution and Recovery}

Based on the research hypothesis, the research model of this paper consists of five aspects, including network convergence, interdependence, sense of community, relationship switching costs and game loyalty. According to the characteristics of domestic online game players, the scale of each variable was modified to meet the research purpose, and the first draft of the questionnaire "online gamer identity and game loyalty" was completed. All questionnaire questions were answered by 5-point scale (very inconsistent $=1$, not consistent $=2$, neutral $=3$, very consistent $=4$, very consistent $=5$ ). The respondents were mainly interested in online games.

Descriptive statistics of demographic variables include gender, age, education, occupation and income. Among the 463 valid questionnaires collected, 356 $(76.9 \%)$ were male and $107(23.1 \%)$ were female, with a male to female ratio of $3: 1$.The age of the surveyors mainly ranged from 24 to 28 years old (51.6\%), and the proportion of the respondents with bachelor degree was the highest (44.0\%). In terms of their occupation, sales personnel $(28.8 \%)$ accounted for the majority. In the surveyors' monthly income, 2000 yuan or less accounted for the highest proportion $(40 \%)$

The questionnaire, including 31 items, is divided into eight parts. Owing to space limitations, it will not be completely showed in this paper. The seventh part is "Gamer Identity" measured by Figure 2.The overlapping part of the two circles in each figure from 1 to 7 represents the degree of closenness between players and online games, and the larger the value is, the more inseparable the players and online games are.

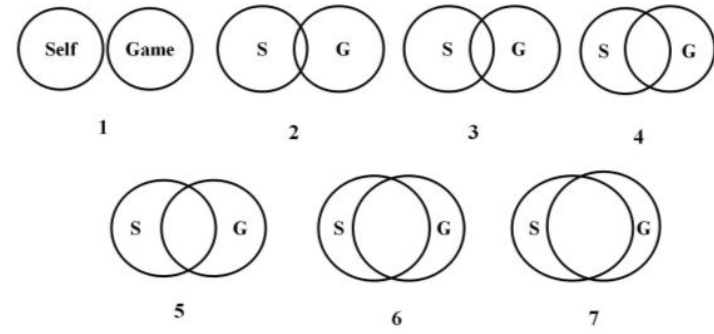

Figure 2 Inclusion of ingroup in the self.

\subsection{Hypothesis Testing}

In order to improve the validity of the questionnaire, when analyzing the core variables, this paper removes 
the questionnaire that has not played games in the last half month.

According to Figure 2, respondents who selected 1, 2, 3 and 4 were classified as low game identification group. Respondents who selected 5, 6 and 7 were classified as high game identification group.

Table 1. Mean value of high and low gamer identity

\begin{tabular}{|lc|c|c|c|c|}
\hline & $\begin{array}{l}\text { Gamer } \\
\text { Identity }\end{array}$ & $\mathrm{N}$ & Mean & $\begin{array}{c}\text { Std. } \\
\text { deviation }\end{array}$ & $\begin{array}{c}\text { Std. } \\
\text { Error } \\
\text { mean }\end{array}$ \\
\hline Network & $>=5$ & 138 & 3.1599 & 1.10049 & .09437 \\
Convergence & $<5$ & 320 & 2.0237 & 1.02394 & .05724 \\
\hline Interdependence & $>=5$ & 138 & 3.2319 & 1.17867 & .10034 \\
& $<5$ & 320 & 2.1797 & 1.04940 & .05866 \\
Sense of & $>=5$ & 138 & 3.8152 & 1.00059 & .08518 \\
Community & $<5$ & 320 & 2.6242 & 1.19355 & .06651 \\
\hline Relational & $>=5$ & 138 & 3.5507 & 1.15446 & .09827 \\
Switching Cost & $<5$ & 320 & 2.1801 & 1.13718 & .06337 \\
\hline Game & $>=5$ & 138 & 3.8377 & 0.96131 & .08183 \\
Loyalty & $<5$ & 320 & 2.8696 & 1.21696 & .06782 \\
\hline
\end{tabular}

Table 2. Regression analysis

\begin{tabular}{|c|c|c|c|c|c|c|}
\hline & & ID & $\mathrm{SC}$ & $\mathrm{RSC}$ & GL & $\mathrm{NC}$ \\
\hline Interdependence & & 1 & $.765^{* * *}$ & $.666^{* * *}$ & $.539 * *$ & $.696^{* * *}$ \\
\hline & Sig. & & .000 & .000 & .000 & .000 \\
\hline (ID) & $\mathrm{N}$ & 458 & 458 & 458 & 458 & 454 \\
\hline Sense & $\mathrm{P}$ & $.765^{* *}$ & 1 & $.708^{* * *}$ & $.607 * *$ & $.607^{* * *}$ \\
\hline of Community & Sig. & .000 & & .000 & .000 & .000 \\
\hline (SC) & $\mathrm{N}$ & 458 & 460 & 460 & 460 & 456 \\
\hline Relational & $\mathrm{P}$ & $.666^{* *}$ & $.708^{* *} *$ & 1 & $.613 * *$ & $.597^{* * *}$ \\
\hline Switching Cost & Sig. & .000 & .000 & & .000 & .000 \\
\hline (RSC) & $\mathrm{N}$ & 458 & 460 & 460 & 460 & 456 \\
\hline Game & $\mathrm{P}$ & $.539^{* *}$ & $.607^{* *}$ & $.613^{* * *}$ & 1 & $.499^{* * *}$ \\
\hline Loyalty & Sig. & .000 & .000 & .000 & & .000 \\
\hline (GL) & $\mathrm{N}$ & 458 & 460 & 460 & 460 & 456 \\
\hline Network & $\mathrm{P}$ & $.696^{* *}$ & $.607 * *$ & $.597 * *$ & $.499 * *$ & 1 \\
\hline Convergence & Sig. & .000 & .000 & .000 & .000 & \\
\hline (NC) & $\mathrm{N}$ & 454 & 456 & 456 & 456 & 456 \\
\hline Gamer & $\mathrm{P}$ & $.515^{* *}$ & $.512^{* *}$ & $.580^{* * *}$ & $.497 * *$ & $.508^{* * *}$ \\
\hline Identity & Sig. & .000 & .000 & .000 & .000 & .000 \\
\hline , & $\mathrm{N}$ & 458 & 460 & 460 & 460 & 456 \\
\hline
\end{tabular}

Compared with the mean value of high gamer identity and low gamer identity in 5 variables, high gamer identity assigns higher value than low gamer identity. Gamer identity has a great impact on players' online and off-line behaviors.

Pearson correlation presents the linear relationship between gamer identity and 5 variables. There is a positive and significant relationship between Gamer Identity, Interdependence $(\mathrm{r}=0.515, \mathrm{p}<0.01 * *)$, Sense of Community $\left(\mathrm{r}=0.512, \mathrm{p}<0.01^{* *}\right)$, Relational Switching Cost $(\mathrm{r}=0.580, \mathrm{p}<0.01 * *)$, Game Loyalty $(\mathrm{r}=0.497$, $\left.\mathrm{p}<0.01^{* *}\right)$ and Network Convergence $(\mathrm{r}=0.508$, $\mathrm{p}<0.01 * *)$.

\subsection{Analysis of Game Loyalty Incentives}

Gender is an important indicator for gamer identity. Using the independent sample T-test, we found that there was a significant difference between "gender"and"gamer identity" Males $(\mathrm{M}=3.42)$ were significantly higher than females $(M=2.87)$. However, there was no significant difference between males $(M=3.20)$ and females $(M=3.03)$ in game loyalty. In addition, it is worth noting that in gaming world, the frequency of women playing games $(M=3.24)$ is not much lower than that of men $(M=3.45)$, and the gap between the male and female is very small. Online games are no longer just for men. More and more women are starting to join online games.

Game frequency is significantly correlated with game loyalty and gamer identity. According to the "game loyalty"test, players with high frequency are more likely to make positive comments on the current game. The mean value of each item of high frequency players was higher than that of low frequency players and exceeded 3. In particular, the second test item of "game loyalty" is "I am willing to spend more time playing this online game. "The average value of this item of high frequency players $(\mathrm{M}=3.10)$ is much higher than that of low frequency players $(M=2.06)$. When a player continues to play a game with high frequency, he is willing to continue to spend more time on the game. Game frequency not only affects the players' attitude towards the game, but also, under certain conditions, will aggravate the players' game time and further increase their frequency of playing games.

Through the analysis of differentiation, we find that in addition to "interdependence", there is a significant positive correlation between "network convergence", "relational switching cost", "sense of community" and "game loyalty". "Network convergence" and "relational switching cost"are common factors affecting "game loyalty" and "game identity". In the "sense of community" test, the mean value of high game loyalty is the highest and the difference between high and low 
game loyalty is the most conspicuous. Compared with "network convergence" and "relational switching cost", "sense of community" is a core factor affecting game loyalty.

In terms of the mean value of each item in "sense of community", the average value of each item of high game loyalty exceeds the middle number of 3 . Compared with the mean value of low game loyalty, the difference is obvious. This shows that each item of "sense of community" has certain predictive power for game loyalty. "Sense of community" is a kind of psychological state of people. Previous studies have proved that the "sense of community" is the most significant in online games. Combined with the questionnaire data, we can subdivide the "sense of community" into the following aspects. First of all, in terms of item 1 (I still feel that I am part of this group of friends even though I am in a different place from my online game partner) and item 3 (in the game, I feel that others are trying to build a sense of group, and I will have the same idea), Online games can bring players a sense of belonging and security, which eliminates the loneliness of daily life and builds a virtual community for players. In terms of item 2 (online games allow me to express my emotions and opinions and get to know my online game partners), Online games provide an open communication environment for the players, in such a free atmosphere, players get entertainment or a sense of achievement (item 4: In online games, I complete tasks and achieve game goals with other members).Therefore, as mentioned above, Kim (2011) explained the social presence as follows: (1) a sense of community; (2) mutual attention and support; (3) open communication; (4) effective connectedness. These four dimensions are contained in online games, and online games are also the most significant representative of social presence in today's Internet products.

\section{CONCLUSION AND ENLIGHTENMENT}

This paper analyzes the reasons that affect the "game loyalty" and "gamer identity", and we can draw the following conclusions. First of all, as far as "game loyalty" is concerned, "game frequency", "network convergence", "sense of community" and "relationship switching cost" has a positive impact on it. The high frequency of the game will significantly affect the player's attitude toward the game. In addition, a high frequency of games can make players "addicted" and spend more time in the game. In the "network convergence" incentive analysis, we found that the number of common contacts in online games has a greater impact on "game loyalty". In the analysis of "sense of community", online games provide psychological support for players. Moreover, as far as the "gamer identity" is concerned, "gender", "game frequency", "network convergence" and "relationship switching cost" have positive effects on it. These factors can be divided into two parts: internal and external. From the internal, "game frequency" is a common factor that affects "game loyalty" and "gamer identity", and the effect is significant. In addition, "gender" has no significant effect on "game loyalty". Online gaming is no longer just a male sport. Among the four factors that affect game loyalty, "sense of community" has the most significant effect. On the one hand, online games provide players with a strong sense of social presence. On the other hand, the psychological pressure and demands of players can be solved in online games. From the external reasons, players' social network also affects their loyalty and recognition of the game. Online games are also a kind of social resources. The feelings and contacts accumulated through online games are the reasons why it is difficult for players to give up the game.

After data analysis, all the five hypotheses are established. There is a significant positive correlation between gamer identity and game loyalty and its related indicators. The empirical results show that the reasons that affect the game loyalty and gamer identity. It has certain reference for the development of game industry.

Firstly, the proportion of female players in the game industry is gradually increasing. Compared with men, there is no big gap in the game frequency and loyalty. Therefore, the future development of the game industry should take into account the needs of women, and reserve corresponding space for female players in the aspects of visual packaging, plot setting and character design.

Secondly, the most direct way to keep players is to increase their online time. In the data analysis, we can intuitively see that game frequency has a significant impact on game loyalty and gamer identity. Therefore, a good game should establish a sustainable development model. It is obvious that the development of games should also take the problem of teenagers' addiction into account. Too high frequency of games will lead to more investment in game time, which will do more harm than good for the development of teenagers.

Thirdly, what players seek from online games is not only the physical pleasure, but also the psychological satisfaction. Online games can bring players a virtual sense of community, which is of certain significance to eliminate the loneliness of players' daily life. Therefore, a good online game should allow players get more open social interaction and meet their psychological needs.

Fourthly, the social network of players has a great impact on game loyalty and gamer identity. Therefore, in the design and development of online games, we can create a virtual social system for them. On the one hand, it can build a platform for their psychological demands. On the other hand, stabilizing the social circle of online 
games will strengthen their recognition of the game and enhance their loyalty to the game. Moreover, online games are not only a way of leisure and entertainment. In addition, the related products of online games and their derived contacts and emotions are also a kind of capital for players' social interaction. Therefore, the establishment of social platform for online games is of great significance to retain players.

\section{REFERENCES}

[1] R. iResearch, China Mobile Game Industry Report 2020,

DOI: https://www.iresearch.com.cn/Detail/report?id=367 $9 \&$ isfree $=0$

[2] M. Tajfel, H., Human groups and social categories: Studies in social psychology, Cambridge University Press, 1981.
[3] J. Tropp,L.R., Wright,S.C., Ingroup identification as the inclusion of ingroup in the self, Personal and Social Psychology Bulletin, 27(5), 2001: 585586.

[4] J. Tajfel, H., Turner, J.C., The social identity theory of intergroup behavior, In S.Worschel, W.G.Austin (Eds.), Psychology of intergroup relations, 1986.

[5] J. Frederik De Grove, Cedric Coutois, Jan Van Looy, How to be a gamer! Exploring personal and social indicators of gamer identity, Journal of Computer-Mediated Communication, 20(2015), 346-361.

[6] J. Kim, J., Developing an instrument to measure social presence in distance higher education, British Journal of Educational Technology, 42(5), 763-777, 2011. 